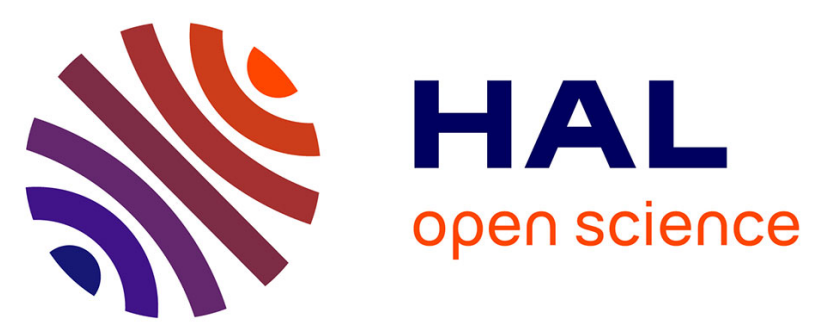

\title{
Determination of plutonium in nitric acid solutions using energy dispersive L X-ray fluorescence with a low power X-ray generator
}

J Py, J.-E Groetz, J.-C Hubinois, D Cardona

\section{- To cite this version:}

J Py, J.-E Groetz, J.-C Hubinois, D Cardona. Determination of plutonium in nitric acid solutions using energy dispersive L X-ray fluorescence with a low power X-ray generator. Nuclear Instruments and Methods in Physics Research Section A: Accelerators, Spectrometers, Detectors and Associated Equipment, 2015, 780, pp.131-137. 10.1016/j.nima.2015.01.073 . hal-01315386

\author{
HAL Id: hal-01315386 \\ https://hal.science/hal-01315386
}

Submitted on 13 May 2016

HAL is a multi-disciplinary open access archive for the deposit and dissemination of scientific research documents, whether they are published or not. The documents may come from teaching and research institutions in France or abroad, or from public or private research centers.
L'archive ouverte pluridisciplinaire HAL, est destinée au dépôt et à la diffusion de documents scientifiques de niveau recherche, publiés ou non, émanant des établissements d'enseignement et de recherche français ou étrangers, des laboratoires publics ou privés. 


\title{
Determination of plutonium in nitric acid solutions using energy dispersive L X-ray fluorescence with a low power X-ray generator
}

\author{
J. Py, ${ }^{\mathrm{a}, \mathrm{b}}$, J.-E. Groetz ${ }^{\mathrm{a}, *}$, J.-C. Hubinois ${ }^{\mathrm{b}}$, D. Cardona ${ }^{\mathrm{b}}$ \\ ${ }^{a}$ Laboratoire Chrono-Environnement, UMR CNRS 6249, Université de Franche-Comté, 16 route de \\ Gray, F-25030 Besançon, France \\ ${ }^{b}$ Commissariat à l'Énergie Atomique, Centre de Valduc, F-21120 Is-sur-Tille, France
}

\begin{abstract}
This work presents the development of an in-line energy dispersive L X-ray fluorescence spectrometer set-up, with a low power X-ray generator and a secondary target, for the determination of plutonium concentration in nitric acid solutions. The intensity of the $\mathrm{L}$ $\mathrm{X}$-rays from the internal conversion and gamma rays emitted by the daughter nuclei from plutonium are minimized and corrected, in order to eliminate the interferences with the L X-ray fluorescence spectrum. The matrix effects are then corrected by the Compton peak method. A calibration plot for plutonium solutions within the range 0.1-20 g. $\mathrm{L}^{-1}$ is given.
\end{abstract}

Keywords: L X-rays, EDXRF, Secondary target, Plutonium, SDD detector, Compton Peak correction

\section{Introduction}

The energy dispersive X-ray fluorescence spectrometry (EDXRF) is used to quantify rapidly, simultaneously and by non-destructive assays, the transuranic elements (uranium, neptunium, plutonium, americium) in liquid wastes from the nuclear reprocessing plants. In the last 30 years, several configurations have been developed to determine in-line transuranic elements by excitation of K-lines from radionuclide sources or X-ray tube [1-4]. Only a few configurations have been developed by excitation of L-lines from radionuclides or X-ray tube, mainly with a wavelength-dispersive X-Ray fluorescence instrument: one is installed in a glove box at the Los Alamos National Laboratory leading to a sensitivity of around $2 \mathrm{ppm}$ for uranium [5-8], another one was installed for in-line processes at AREVA La Hague [9] or CEA Marcoule in France. These devices use a specific detector and a X-ray generator of high power, requiring liquid cooling and a graphite monochromator for selecting the element which will be analysed. Other configurations use HPGe detectors to measure self-induced X-ray fluorescence in spent nuclear fuel [10].

*Corresponding author Tel. : + 33381666507 ; fax: + 33381666522

Email address: jegroetz@univ-fcomte.fr (J.-E. Groetz)

Preprint submitted to Nucl. Instrum. Meth. A

December 24, 2015 
Advanced technology makes now possible a portable device for on-site analysis of the L X-rays transuranic elements by EDXRF without liquid cooling [11], in order to minimize as low as possible the amount of solid or liquid wastes. The purpose of this work is to develop, with an adjustable prototype, a new compact fluorescence L Xray spectrometer and an analytical method to determine on a derivation duct, without dilution, the concentration value of plutonium within 0.1-20 g. $\mathrm{L}^{-1}$ in nitric acid solution $\left(10 \% \mathrm{HNO}_{3}\right)$. In these solutions, the concentration values of uranium and americium are deliberately lower than the limit of detection of the spectrometer $\left(\sim 10 \mathrm{mg} \cdot \mathrm{L}^{-1}\right.$ for a counting time of $300 \mathrm{~s}$ ), so as not to interfere with the plutonium peaks.

\section{Experimental}

For the development of this spectrometer, two thallium standard solutions were firstly used to limit as low as possible the number of experiments with nuclear materials, and secondly, several plutonium solutions were prepared with ultra-pure plutonium standard. Then, these solutions were measured by our L X-ray fluorescence prototype spectrometer (Fig. 1).

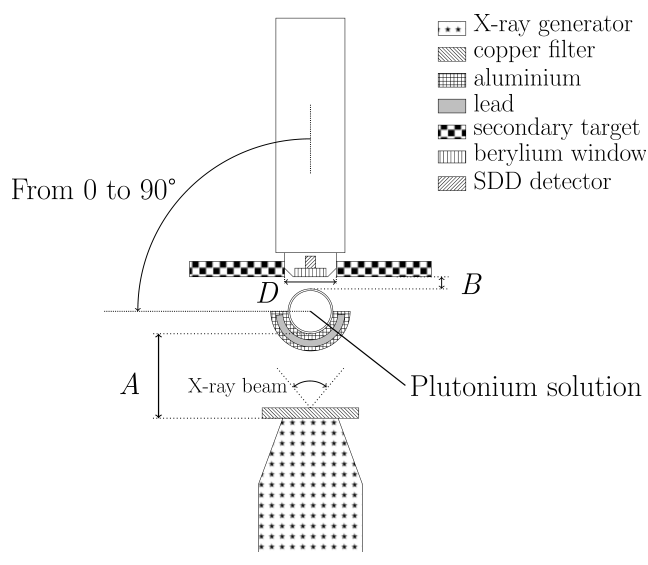

Figure 1: Top view of the L X-ray fluorescence spectrometer used for the determination of plutonium in nitric acid solutions. $A$ : distance from the X-ray generator to the sample. $B$ : distance from the secondary target to the sample. $D$ : diameter of the circular hole for the secondary target.

\subsection{Properties of plutonium standard}

A solid plutonium standard was used to prepare plutonium solutions. This standard has a ${ }_{94}^{239} \mathrm{Pu}$ isotopic concentration higher than $90 \%$ and some radioactive impurities. The concentration values of uranium and americium were analysed in September 2007 by inductively coupled plasma mass spectrometry and inductively coupled plasma atomic emission spectroscopy respectively, at $31 \mu \mathrm{g} / \mathrm{g}$ and $18 \mu \mathrm{g} / \mathrm{g}$. These concentration values were then evaluated at the date of the experiments with an internal CEA evolution code of isotopic composition. The ${ }^{241} \mathrm{Am}$ concentration value (from the $\beta^{-}$decay of ${ }_{94}^{241} \mathrm{Pu}$ with a half-life of 14.29 years), is evaluated at $33 \mu \mathrm{g} / \mathrm{g}$. The total uranium concentration is evaluated at $200 \mu \mathrm{g} / \mathrm{g}$. 


\subsection{Plutonium solution preparation}

Plutonium solutions were prepared in glovebox by using this solid standard Pu diluted in nitric acid solution and $18.2 \mathrm{M} \Omega . \mathrm{cm}$ deionised water. From this solution, five samples were prepared into $5 \mathrm{~mL}$ volumetric flasks in $10 \% \mathrm{HNO}_{3}$, containing respectively 19.98 , $9.99,4.99,9.99 .10^{-1}$ and $9.99 .10^{-2}$ g. $\mathrm{L}^{-1}$ of plutonium. Flasks are in polypropylene (PP, $1 \mathrm{~mm}$ thick, $90 \mathrm{~mm}$ high and diameter of $12 \mathrm{~mm}$ ) and are moved out of the glovebox to be measured by XRF. Flasks were then put into a double flexible plastic shield made up of ethylene-vinyl acetate and ethylene-butyl acrylate (EVA/EBA), each one $0.3 \mathrm{~mm}$ thick and a width of $14 \mathrm{~cm}$, in order to confine radioactive elements and to protect operators.

\subsection{Instrumentation}

To decrease as low as possible the amount of solid or liquid nuclear wastes, the instrumentation requires compact devices without liquid cooling. If the plutonium detection limit is higher than 0.1 g. $\mathrm{L}^{-1}$, a low power X-ray generator cooled by thermal conduction could be used. The X-ray generator is a $50 \mathrm{kV}$ MAGNUM Cabled (Moxtek, USA) made up of a tungsten filament, a silver target metal $(\mathrm{Ag})$ and a beryllium window of 0.25 mm thick. The voltage can be adjusted from 10 to $50 \mathrm{kV}$ and the beam current up to $200 \mu \mathrm{A}$; the maximum power for the $\mathrm{X}$-ray production is $10 \mathrm{~W}$. The $\mathrm{X}$-ray generator is operated with a Moxtek FTC-200 Controller. Firstly, the X-ray generator parameters are adjusted during experiments at $50 \mathrm{kV}$ and $50 \mu \mathrm{A}$. The fluorescence X-rays emitted from the sample are measured between 0.2 and $20 \mathrm{keV}$ by a silicon drift detector (SDD) cooled with a Peltier module (Ketek, Germany) with a beryllium window of $8 \mu \mathrm{m}$ thick and a detection area of $7 \mathrm{~mm}^{2}$. The energy resolution at $5.8 \mathrm{keV}$ is $148 \mathrm{eV}$ and the shaping time of the detector amplifier is $2 \mu \mathrm{s}$. The analog signal from the amplificator was converted into a digital signal by an analog-to-digital converter (ADC, KeteK) and is analysed through a multichannel analyser with 4096 channels (MCA, Ketek) to generate the spectra with the MCDWIN software. The intensity of L X-rays was determined by a Gaussian fit.

The distance $A$ between the X-ray generator and the sample and the distance $B$ between the secondary target and the sample are controlled through a graphical user interface and electric motors. The distance between the X-ray generator and the sample ranges from 12 to $40 \mathrm{~mm}$ and the distance between the secondary target and the sample varies within limits of $3 \mathrm{~mm}$ and $30 \mathrm{~mm}$. The detector angular position ranges from $0^{\circ}$ to $90^{\circ}$.

A big circular secondary target is placed in front of the detector (section 3.1). Its characteristics are $50 \mathrm{~mm}$ in diameter and $2 \mathrm{~mm}$ thick. A circular aperture takes place at the centre of the secondary target so that X-rays emitted by the sample reaches the detector.

A lead half protection of $1.14 \mathrm{~mm}$ thick covered with a $0.7 \mathrm{~mm}$ thick aluminium sheet is used to stop the polychromatic radiations from the X-ray generator and to protect operators from the lead toxicity.

To analyse plutonium samples in a double plastic shield (EVA/EBA), an aluminium sample support has been designed with a container to maintain and protect the plastic shield, and to contain the solution in case of vial leak (Fig. 2).

These instruments are in a lead box $(50 \mathrm{~cm} \times 50 \mathrm{~cm} \times 65 \mathrm{~cm})$ to protect operators from X-rays. 


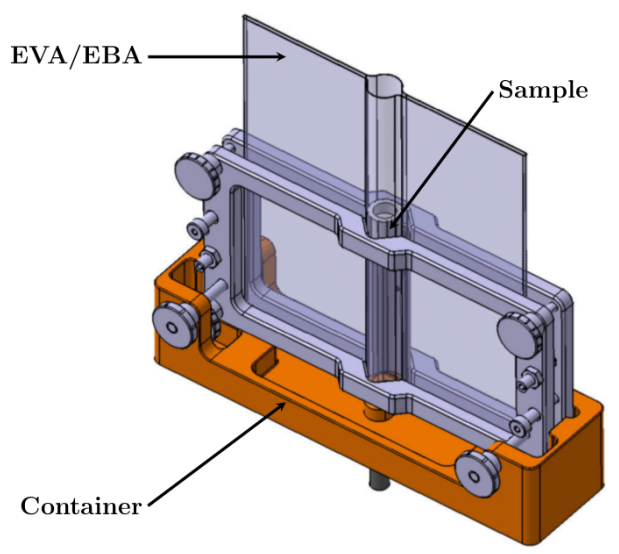

Figure 2: Support used to analyse plutonium samples.

\section{Determination of the optimum geometry}

\subsection{Requirements}

The interpretation of X-rays spectra from plutonium samples must be carefully performed with portable EDXRF instruments, as the peak intensities are not necessarily correlated with the concentration values of the elements [12]. Daughter nuclei can be in excited states after alpha decays from ${ }_{94}^{238} \mathrm{Pu}$ to ${ }_{92}^{234} \mathrm{U}$, from ${ }_{94}^{239} \mathrm{Pu}$ to ${ }_{92}^{235} \mathrm{U}$, from ${ }_{94}^{240} \mathrm{Pu}$ to ${ }_{92}^{236} \mathrm{U}$ and from ${ }_{94}^{242} \mathrm{Pu}$ to ${ }_{92}^{238} \mathrm{U}$. Two relaxation processes are then possible: either $\gamma$-rays are emitted with an energy generally higher than $50 \mathrm{keV}$ [13], or X-rays from daughter nucleus are emitted from an internal conversion. Thus X-rays from internal conversion and $\gamma$-rays from de-excitation of the nuclear state are added to the characteristic X-rays from fluorescence. The use of the detector in the range $0.2-20 \mathrm{keV}$ has the advantage to eliminate most of $\gamma$-rays, and avoid high saturation of the SDD detector. As an example, a low concentration of americium can saturate the detector because of two highly intense gamma peaks at $26.3 \mathrm{keV}$ and $59.5 \mathrm{keV} \mathrm{[5].} \mathrm{In} \mathrm{the} \mathrm{present} \mathrm{case,} \mathrm{the} \mathrm{problem} \mathrm{of}$ $\mathrm{L} \mathrm{X}$-rays line analysis is mainly limited to the interference between X-rays from internal conversion and X-rays from fluorescence.

Two solutions are possible to correct the interference due to internal conversion and to correlate the peak intensities to the concentration values of elements. The first solution is to use a high powered X-ray source which requires in some cases a collimator in front of the detector $[2,12,14]$. The second solution is to perform a subtraction process between an active spectrum (with the X-ray generator) and a passive background spectrum where only X-rays from internal conversion and $\gamma$-rays due to plutonium isotopes are measured [14]. Since a low power X -ray generator is used, the yield of the irradiation of the plutonium samples is optimized to use as far as possible the low X-ray flux emitted by the generator, to increase the intensity of L X-ray fluorescence and to carry out a unique measurement. This is the reason why the X-ray generator is not collimated in this work. If the decay background is significant compared to the intensity of fluorescence $\mathrm{X}$-rays, it is subtracted to the active spectrum. 
When the concentration values of elements are higher than several g. $\mathrm{L}^{-1}$, X-rays fluorescence are self-absorbed, absorbed and enhanced by nearby atoms $[5,15,16]$. These effects must be corrected by rigorous analysis techniques to accurately determine the concentration of elements (with an uncertainty lower than 10\%). Several possible corrections exist $[17,18]$ to fix the absorption effects:

1. the linear approximation with a thin sample, or a low concentration or a constant matrix,

2. the method which represents the intensity of X-rays as a function of the element concentration,

3. the method with internal element standardisation,

4. the dilution,

5. the Compton peak correction.

Items 1 and 2 are intended for a simple analysis and could lead to large errors. The methods by internal element standardisation or by dilution are not adapted because additional preparations are required in these cases. The Compton correction could be used, because the intensity of the Compton scattered radiation from an X-ray source gives an estimation of the absorption coefficient of the whole sample [18]. The Ag$\mathrm{K}_{\alpha_{1}}$ ray emitted by the $\mathrm{X}$-ray generator is higher than $20 \mathrm{keV}$ and is not detected by our SDD detector. The use of a secondary target, which is a technique to produce quasi-monochromatic secondary X-rays, should enable the measurement of the Compton scattered radiation below $20 \mathrm{keV}$.

\subsection{Choice of the secondary target}

The molybdenum was unsuited because the Mo- $\mathrm{K}_{\alpha_{1}}$ fluorescence energy $(17.48 \mathrm{keV}$, see Table 1) is lower than the $\mathrm{L}_{3}$-edge of plutonium $\left(\mathrm{L}_{3}\right.$-edge $\left.=18.06 \mathrm{keV}\right)$. The use of a secondary technetium target $\left(\mathrm{Tc}-\mathrm{K}_{\alpha_{1}}=18.37 \mathrm{keV}\right)$ was impossible insofar as this element is radioactive and difficult to manipulate. Electrons from $L_{2}$ and $L_{1}$ shells of plutonium

\begin{tabular}{lcccc}
\hline Element & ${ }_{42} \mathrm{Mo}$ & ${ }_{43} \mathrm{Tc}$ & ${ }_{44} \mathrm{Ru}$ & ${ }_{45} \mathrm{Rh}$ \\
\hline Energy of $\mathrm{K}_{\alpha_{1}}(\mathrm{keV})$ & 17.48 & 18.37 & 19.28 & 20.22 \\
\hline
\end{tabular}

Table 1: Parameters for the choice of element for the secondary target.

are not ejected with the $\mathrm{Ru}-\mathrm{K}_{\alpha_{1}}$ line because the absorption edges are equal to 22.26 $\mathrm{keV}\left(\mathrm{L}_{2}\right.$-edge) and $23.11 \mathrm{keV}\left(\mathrm{L}_{1}\right.$-edge). The strongest plutonium $\mathrm{X}$-ray lines should be the lines from the $\mathrm{L}_{3}$-shell, namely: $\mathrm{L}_{\alpha_{1,2}}, \mathrm{~L}_{\beta_{2}}, \mathrm{~L}_{\beta_{6}}, \mathrm{~L}_{\beta_{15}}$ and $\mathrm{L}_{l}$ (Table 2). A secondary target in ruthenium (purity of $99.9 \%$ ) was chosen, because ruthenium is the only natural and non radioactive element with a $\mathrm{K}_{\alpha_{1}}$ fluorescence energy lower than $20 \mathrm{keV}$ and higher than the $\mathrm{L}_{3}$-edge of plutonium. The ruthenium metal is unfortunately an extremely hard and brittle material and consequently, difficult to machine for making a circular hole in the centre of secondary target. The diameter of the circular hole was $15 \mathrm{~mm}$.

\subsection{Pre-optimization of geometric parameters for the spectrometer}

In order to minimize the number of experiments with plutonium samples, a pre-study is first performed with a 10 g. $\mathrm{L}^{-1}$ thallium standard solution in $10 \% \mathrm{HNO}_{3}$. In this way, 


\begin{tabular}{lcccccc}
\hline X-ray line & $\mathrm{Pu}-\mathrm{L}_{l}$ & $\mathrm{Pu}-\mathrm{L}_{\alpha_{2}}$ & $\mathrm{Pu}-\mathrm{L}_{\alpha_{1}}$ & $\mathrm{Pu}-\mathrm{L}_{\beta_{15}}$ & $\mathrm{Pu}-\mathrm{L}_{\beta_{2}}$ & $\mathrm{Pu}-\mathrm{L}_{\beta_{6}}$ \\
\hline Energy (keV) & 12.12 & 14.08 & 14.27 & 17.20 & 17.25 & 16.49 \\
Probability & $2.210^{-2}$ & $3.610^{-2}$ & $3.110^{-1}$ & $7.310^{-3}$ & $6.710^{-2}$ & $5.810^{-3}$ \\
\hline
\end{tabular}

Table 2: Energy of X-ray and probability for radiative transition filling a vacancy in the $\mathrm{L}_{3}$-shell of plutonium $[13,21,22]$.

distances $B$ (sample-secondary target) and $A$ (X-ray generator-sample) are optimised to increase the intensity of the Tl- $\mathrm{L}_{\alpha_{1,2}}$ and Compton peaks. The detector is aligned with the sample and the X-ray generator to irradiate at the maximum the secondary target.

To optimize these positions, the intensities of peaks of interest are measured according to the region of interest (ROI) showed in figure 3, during $300 \mathrm{~s}$ without the double plastic shield. The intensity of theses lines increases when the distance $B$ is smaller and is maximum when the secondary target is closest to the sample (Tables 3 and 4 ). The maximum intensity is obtained at $A=40 \mathrm{~mm}$ and $B=3 \mathrm{~mm}$.

\begin{tabular}{lccccccc}
\hline $\mathrm{B}=$ Secondary target position & $3 \mathrm{~mm}$ & $5 \mathrm{~mm}$ & $10 \mathrm{~mm}$ & $15 \mathrm{~mm}$ & $20 \mathrm{~mm}$ & $25 \mathrm{~mm}$ & $30 \mathrm{~mm}$ \\
\hline Tl- $\mathrm{L}_{\alpha_{1,2}}$ (counts) & 122902 & 103957 & 51091 & 22312 & 9733 & 4167 & 985 \\
Compton (counts) & 281823 & 278283 & 155832 & 76433 & 36094 & 16013 & 3532 \\
\hline
\end{tabular}

Table 3: Intensity of X-rays as a function of the secondary target position ( $\mathrm{mm})$, with the X-ray generator position at $20 \mathrm{~mm}$.

\begin{tabular}{lccccccc}
\hline $\mathrm{A}=$ X-ray generator position & $12 \mathrm{~mm}$ & $15 \mathrm{~mm}$ & $20 \mathrm{~mm}$ & $25 \mathrm{~mm}$ & $30 \mathrm{~mm}$ & $35 \mathrm{~mm}$ & $40 \mathrm{~mm}$ \\
\hline${\text { Tl- } \alpha_{\alpha_{1,2}} \text { (counts) }}_{\text {Compton (counts) }}^{6131}$ & 28334 & 122902 & 229590 & 300738 & 328206 & 351195 \\
& 11817 & 62825 & 281823 & 527287 & 655876 & 745867 & 821088 \\
\hline
\end{tabular}

Table 4: Intensity of X-rays as a function of the X-ray generator position (mm), with the secondary target position at $3 \mathrm{~mm}$.

A copper filter of $0.1 \mathrm{~mm}$ thick is put in front of the X-ray generator to absorb bremsstrahlung (Fig. 3), which increases the signal-to-noise ratio (SNR) for the sample analysis within the range 0.1-20 g. $\mathrm{L}^{-1}$. Fig. 3 shows the Tl- $\mathrm{L}_{\alpha_{1,2}}$ peak $(10.27 \mathrm{keV})$, the Compton peak, the Rayleigh peak $\left(\mathrm{Ru}-\mathrm{K}_{\alpha_{1}}=19.28 \mathrm{keV}\right)$ and artefact peaks. The intensity of bremsstrahlung decreases about $80 \%$ whereas the intensity of Tl- $\mathrm{L}_{\alpha_{1,2}}$ and Compton peaks decreases respectively of $62 \%$ and $57 \%$. The SNR is now acceptable.

The detection limit (DL) is calculated according to the following relation using a $50 \mathrm{mg} . \mathrm{L}^{-1}$ thallium sample without a double plastic shield in $10 \% \mathrm{HNO}_{3}$ :

$$
D L=\frac{3 \sigma}{S}
$$

where $\sigma$ is the standard deviation of the signal from thallium obtained after ten analysis of blank solutions and $S$ is the sensitivity of the Tl- $\mathrm{L}_{\alpha_{1,2}}$ peak (cps.L.mg ${ }^{-1}$ ). The calculated detection limit using a copper filter is acceptable $\left(\approx 7 \mathrm{mg} \cdot \mathrm{L}^{-1}\right)$ in our case. Although the intensity of the Tl- $\mathrm{L}_{\alpha_{1,2}}$ peak is approximately $30 \%$ lower with a double plastic shield (EVA/EBA), plutonium samples should be quantified above $100 \mathrm{mg} \cdot \mathrm{L}^{-1}$. 


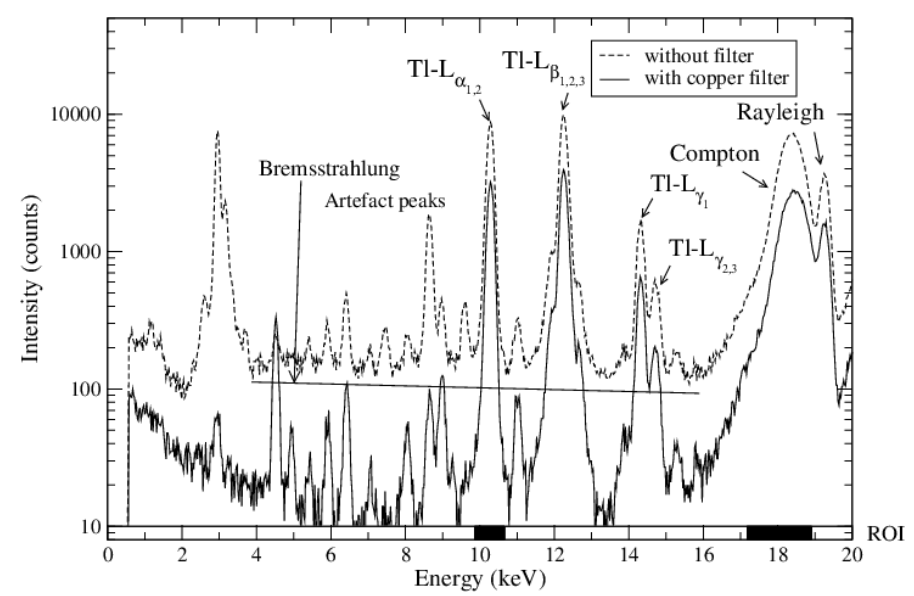

Figure 3: XRF spectra of a 10 g. $\mathrm{L}^{-1}$ thallium sample in $10 \% \mathrm{HNO}_{3}$, analysed during 300 seconds with a secondary target position at $3 \mathrm{~mm}$ and the X-ray generator position at $40 \mathrm{~mm}$. The different ROI are specified on the energy axis with black rectangles.

\subsection{Compton correction for matrix effects}

The intensity of the Compton scattered radiation from a X-ray source can be used to obtain an estimation of the absorption coefficient of the specimen at the scattered wavelength $\left(\lambda_{\text {scat }}\right)$. The intensity of the Compton scatter peak $\left(I_{\text {Compton }}\right)$ is inversely proportional to the mass attenuation coefficient $\mu_{\text {sol }}[18,19]$ :

$$
I_{\text {Compton }}\left(\lambda_{\text {scat }}\right) \propto \frac{1}{\mu_{\text {sol }}\left(\lambda_{\text {scat }}\right)}
$$

As the enhancement effects can be neglected, the fluorescence intensity $I_{i}$ of the element $i$ is equal to :

$$
I_{i} \propto \frac{C_{i}}{\mu_{\text {sol }}} \sim C_{i} \times I\left(\lambda_{\text {Compton }}\right)
$$

This method is limited to those cases where trace element have their L-edges between their L X-lines and the scattered peaks. Thus the plutonium concentration is determined according to the following relation:

$$
\frac{I_{P u-L_{\alpha_{1,2}}}}{I_{\text {Compton }}}=a C+b
$$

where $I_{\mathrm{Pu}-\mathrm{L}_{\alpha_{1,2}}}$ is the $\mathrm{Pu}-\mathrm{L}_{\alpha_{1,2}}$ peak count rate, $I_{\text {Compton }}$ is the $\mathrm{Ru}$ Compton $\mathrm{K}_{\alpha}$ peak count rate, $C$ is the plutonium concentration, $a$ and $b$ are regression coefficients. Results from the Compton correction are shown in section 4.2 .

\section{Results and discussion}

\subsection{Internal conversion}

A plutonium sample at the concentration of 19.98 g. $\mathrm{L}^{-1}$ in $10 \% \mathrm{HNO}_{3}$ is measured during $300 \mathrm{~s}$ with an X-ray generator position at $48 \mathrm{~mm}$ (X-ray generator at $50 \mathrm{kV}$ and 50 
$\mu \mathrm{A}$ ) and an secondary target position of $2 \mathrm{~mm}$. As shown with the thallium samples, some artefact peaks and Compton and Rayleigh peaks are measured (Fig. 4). The plutonium fluorescence X-rays are generated from vacancies in the $\mathrm{L}_{3}$-shell, leading to the $\mathrm{Pu}-\mathrm{L}_{l}$, $\mathrm{Pu}-\mathrm{L}_{\alpha_{1,2}} \mathrm{Pu}-\mathrm{L}_{\beta_{6}}$ and $\mathrm{Pu}-\mathrm{L}_{\beta_{2,15}}$ lines. However, the intensity of $\mathrm{Pu}-\mathrm{L}_{\beta_{2,15}}$ line should not be equivalent to the intensity of $\mathrm{Pu}-\mathrm{L}_{\alpha_{1,2}}$ line due to a smaller transition probability (Table 2). The $\mathrm{Pu}-\mathrm{L}_{\beta_{2,15}}$ peak is also overlapped with the $\mathrm{U}-\mathrm{L}_{\beta_{1}}$ peak, given that the $\mathrm{U}-\mathrm{L}_{l}, \mathrm{U}_{\mathrm{L}} \mathrm{\alpha}_{1,2}, \mathrm{U}_{-} \mathrm{L}_{\beta_{2}}$ lines are produced. Although the total uranium concentration (4 $\mathrm{mg} . \mathrm{L}^{-1}$ ) is lower than the detection limit, the intensity of the $\mathrm{U}-\mathrm{L}_{\alpha_{1,2}}$ peak is about $60 \%$ of the intensity of the $\mathrm{Pu}-\mathrm{L}_{\alpha_{1,2}}$ peak.

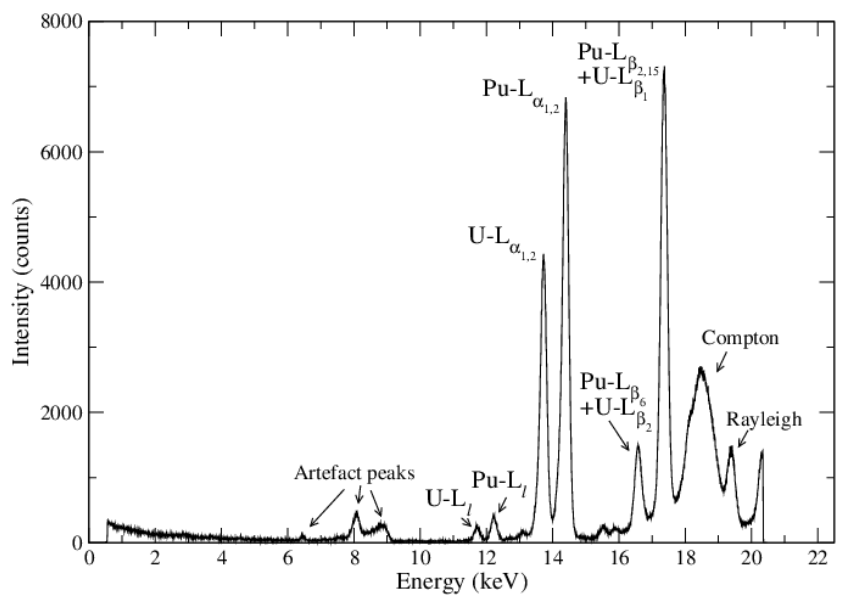

Figure 4: Active spectrum of a plutonium sample at 19.98 g. $\mathrm{L}^{-1}$ in $10 \% \mathrm{HNO}_{3}$, analysed during 300 seconds.

A passive spectrum has been recorded during $300 \mathrm{~s}$ to determine the effects from the radioactive decay. Fig. 5 shows the presence of intense U-L peaks due to internal conversion and two $\gamma$-ray energies. The intensity of the $\mathrm{U}-\mathrm{L}_{\alpha_{1,2}}$ passive peak is nevertheless higher than the $\mathrm{U}-\mathrm{L}_{\alpha_{1,2}}$ active one. To understand this fact, the repeatability of the measurement of $\mathrm{U}_{-} \mathrm{L}_{\alpha_{1,2}}$ peaks (ROI in Fig. 5) and the SDD dead time are determined with:

- three passive measurements during $300 \mathrm{~s}$,

- three active measurements during $300 \mathrm{~s}$.

None of parameters is modified between the different measurements.

The repeatability of the $\mathrm{U}-\mathrm{L}_{\alpha_{1,2}}$ passive and active peak measurements is satisfactory, meaning that for these elements and in this range of concentration, the number of X-rays from internal conversion is constant during $300 \mathrm{~s}$ (Table 5). We can conclude that X-rays from internal conversion combined with the fluorescence X-rays increase the SDD dead time for the active spectrum.

In order to reduce the background due to internal conversion, the diameter of the circular aperture at the centre of the secondary target is decreased. It is reduced from $15 \mathrm{~mm}$ to $5 \mathrm{~mm}$ and then $2 \mathrm{~mm}$ (Fig. 6). Fig. 7 shows the decrease in the intensities of the X-ray peaks from internal conversion. The intensity of $\mathrm{Pu}-\mathrm{L}$ and Compton peaks 


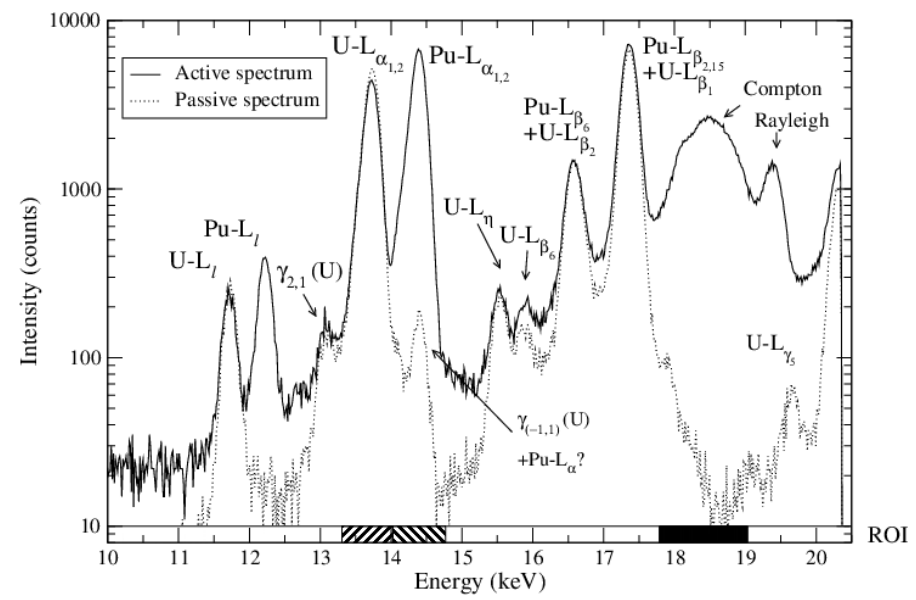

Figure 5: Active and passive spectra of plutonium sample at the concentration of 19.98 g. $\mathrm{L}^{-1}$ in $10 \%$ $\mathrm{HNO}_{3}$, analysed during 300 seconds. The different ROI are specified on the energy axis with black and hatched rectangles.

\begin{tabular}{lcccc}
\hline & \multicolumn{2}{c}{$\mathrm{U}^{-\mathrm{L}_{\alpha_{1,2}}}$} & \multicolumn{2}{c}{ Spectra } \\
& $\begin{array}{c}\text { Average intensity } \\
\text { (counts) }\end{array}$ & $\begin{array}{c}\text { Repeatability } \\
(\%)\end{array}$ & $\begin{array}{c}\text { Average intensity } \\
(\text { counts })\end{array}$ & $\begin{array}{c}\text { Dead time } \\
(\%)\end{array}$ \\
\hline Passive & 236839 & 0.54 & 835135 & 3.05 \\
Active & 196596 & 0.13 & 2070948 & 12.70 \\
Difference (\%) & -17 & & & \\
\hline
\end{tabular}

Table 5: Repeatability of analysis for the $\mathrm{U}-\mathrm{L}_{\alpha_{1,2}}$ peak and dead time of SDD detector, measured for a plutonium sample at the concentration of $19.98 \mathrm{~g} \cdot \mathrm{L}^{-1}$.

decreased in the same proportion. The detector dead time is also reduced at $2.8 \%$ for a diameter of $5 \mathrm{~mm}$ and $0.7 \%$ for a diameter of $2 \mathrm{~mm}$. Moreover, the use of the secondary target with a circular aperture of $2 \mathrm{~mm}$ diameter decreases the artefact peaks, allowing the detection of impurities such as iron $\left(\mathrm{K}_{\alpha_{1}}=6.40 \mathrm{keV}\right)$ and copper $\left(\mathrm{K}_{\alpha_{1}}=8.04 \mathrm{keV}\right)$.

Using this secondary target, the X-ray generator is operated at the maximum power $(200 \mu \mathrm{A})$ in order to intensify the Pu-L and the Compton peaks (Fig. 8). The SDD dead time is $2.66 \%$. The intensity of $\mathrm{U}-\mathrm{L}_{\alpha_{1,2}}$ active peak is now lower compared to the intensity of $\mathrm{Pu}-\mathrm{L}_{\alpha_{1,2}}$ and is similar to the intensity of $\mathrm{U}-\mathrm{L}_{\alpha_{1,2}}$ passive peak. As the intensity of $\mathrm{X}$-rays from internal conversion is not negligible after these optimizations, the passive spectrum is subtracted to the active spectrum. The spectrum of the plutonium sample at 19.98 g. $\mathrm{L}^{-1}$ shows the X-rays of plutonium from $\mathrm{L}_{3}$-shell, the Compton and Rayleigh peaks (Fig. 9). Nevertheless an important noise remains after subtraction for the U-L $\mathrm{L}_{\alpha_{1,2}}$ peak. In these conditions, the quantification of uranium in low concentration together with a high plutonium concentration could be difficult to perform. 


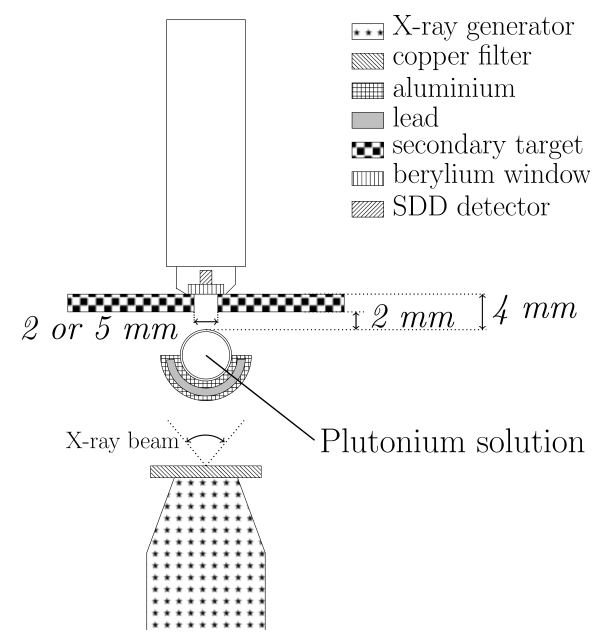

Figure 6: Set-up with a smaller diameter for the aperture in the secondary target.

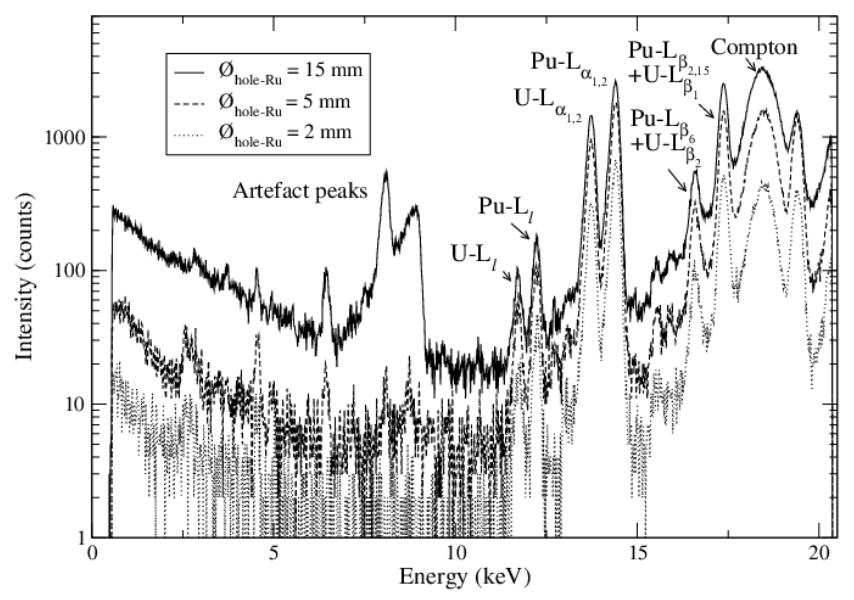

Figure 7: Active spectra of a plutonium sample at 4.995 g. $\mathrm{L}^{-1}$ in $10 \% \mathrm{HNO}_{3}$ for three aperture diameters in the secondary target, measured for $300 \mathrm{~s}$.

\subsection{Correction of matrix effects}

All plutonium samples are analysed during $300 \mathrm{~s}$ with the last configuration. After the subtraction of the passive spectrum to the active spectrum, the intensity of the $\mathrm{Pu}-\mathrm{L}_{\alpha_{1,2}}$ peak is determined for each plutonium sample with the MCDWIN software in the region of interest (Fig. 5 and Table 6). The intensity of this peak increases more weakly than the plutonium concentration (Fig. 10): the curve is concave due to the self-absorption of the $\mathrm{Pu}-\mathrm{L}_{\alpha_{1,2}}$ lines by the sample.

As the Compton peak is observed on every XRF spectrum, the method by the Compton peak correction can be used to fix matrix effects. The intensity of the Compton peak is determined with the MCDWIN software for each plutonium sample in the region of interest (Fig. 5 and Table 6). It is noticed that for the highest values of plutonium 


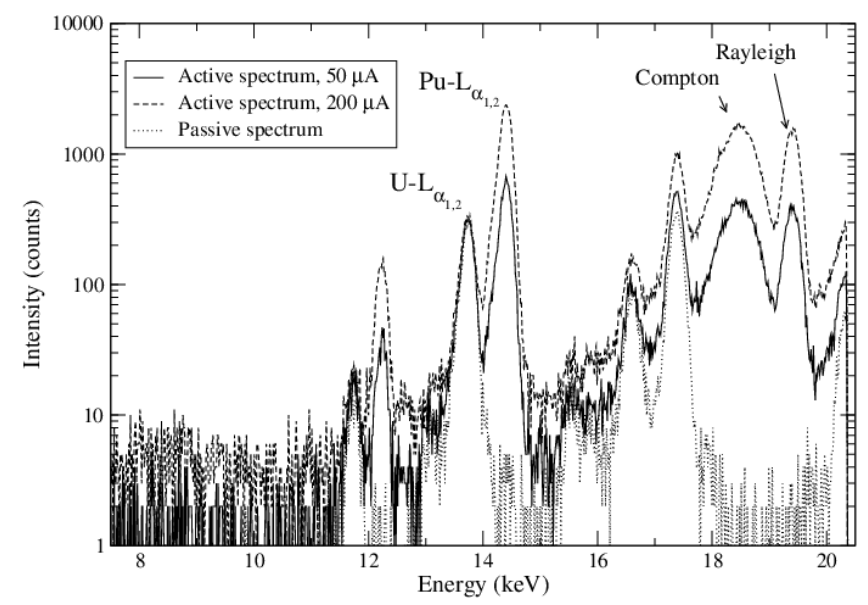

Figure 8: Active and passive spectra of a plutonium sample at 4.995 g.L $\mathrm{L}^{-1}$ in $10 \% \mathrm{HNO}_{3}$ with a hole of $2 \mathrm{~mm}$ diameter in the secondary target, analysed during $300 \mathrm{~s}$.

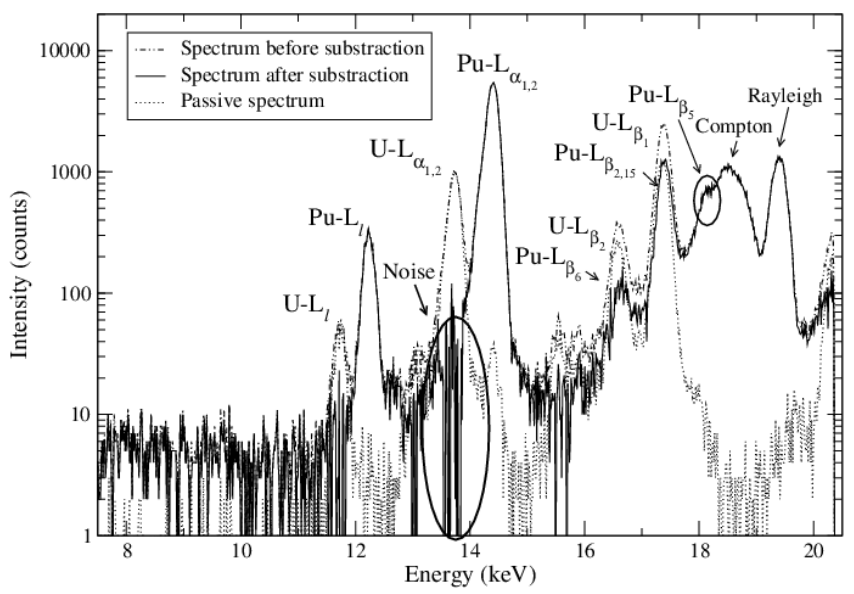

Figure 9: Spectra of a plutonium sample at 19.98 g. $\mathrm{L}^{-1}$ in $10 \% \mathrm{HNO}_{3}$ with a hole of 2 mm diameter in the secondary target and a X-ray generator beam at $200 \mu \mathrm{A}$, analysed during 300 seconds.

concentration, the Compton peak has not a perfect Gaussian shape, due to a shoulder (Fig. 9 and Fig. 11). This shoulder, which is insignificant in relation to the Compton peak for plutonium concentrations lower than $10 \mathrm{~g} . \mathrm{L}^{-1}$, is caused by the interference of the $\mathrm{Pu}_{-} \mathrm{L}_{\beta_{5}}$ (at $17.96 \mathrm{keV}$ ) and $\mathrm{Pu}-\mathrm{L}_{\beta_{1}}$ (at $18.29 \mathrm{keV}$ ) X-ray fluorescence.

The MCDWIN software is inappropriate to process and unfold such a complex spectrum, therefore the peaks in the region of interest are fitted by various mathematical functions with the COLEGRAM software [23, 24], in order to separate accurately the overlapped peaks (Fig. 12). In addition to the $\mathrm{Pu}-\mathrm{L}_{\beta_{5}}$ peak, the $\mathrm{Pu}-\mathrm{L}_{\beta_{1}}$ peak is also fitted at $18.29 \mathrm{keV}$, because the upper part of the X-ray incident spectrum from the secondary target could eject electrons from $\mathrm{L}_{2}$ and $\mathrm{L}_{1}$ shells in plutonium, leading to the the $\mathrm{Pu}-\mathrm{L}_{\beta_{1}}$ line. These plutonium X-ray peaks are fitted by Voigt functions with a 


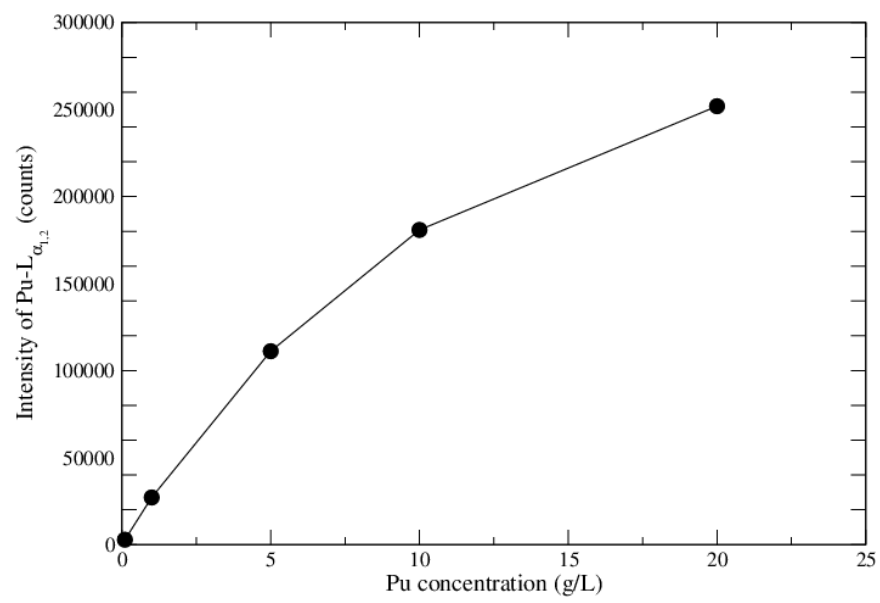

Figure 10: Matrix effects on the $\mathrm{Pu}-\mathrm{L}_{\alpha_{1,2}}$ peak.

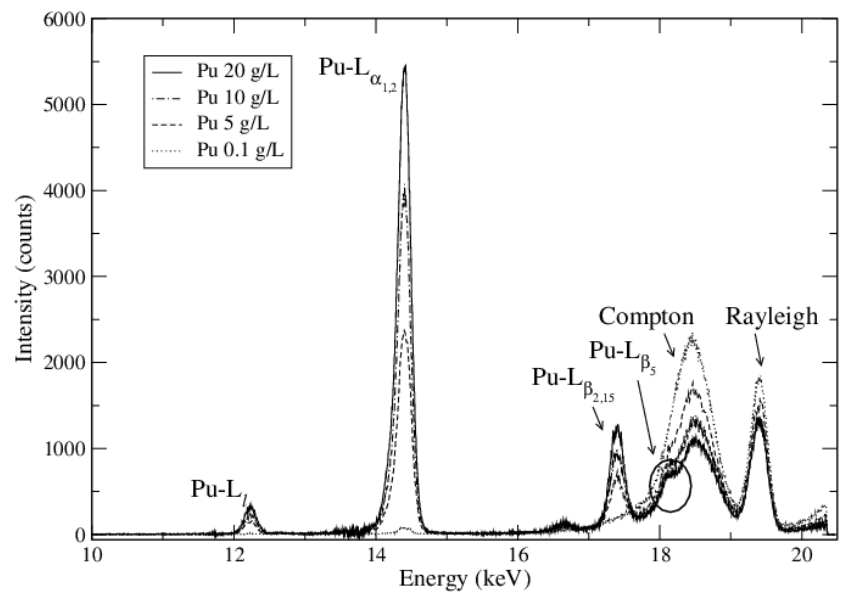

Figure 11: Peak intensities for various plutonium concentration values.

left-hand tail, as the shape of X-ray peaks is the result of a convolution of a Lorentzian function with a Gaussian function and combined with the incomplete charge collection in the SDD detector. The Compton peak is fitted by a Gaussian function with a left-hand tail. When the Compton peak shows this shoulder, the proportion of the intensity of the $\mathrm{Pu}-\mathrm{L}_{\beta_{5}}$ peak and the $\mathrm{Pu}-\mathrm{L}_{\beta_{1}}$ peak is then subtracted to the intensity of the Compton peak according to the relation:

$$
I_{\text {Compton }}^{\text {corrected }}=I_{\text {Compton }}^{\mathrm{MCDWIN}} \times\left(1-\frac{I_{P u-L_{\beta_{5}}}^{\text {COLEGRAM }}}{I_{\text {Compton }}^{\text {COLEGR }}}-\frac{I_{P u-L_{\beta_{1}}}^{\text {COLEGRAM }}}{I_{\text {Compton }}^{\text {COLEGR }}}\right)
$$

The subtraction of the $\mathrm{Pu}-\mathrm{L}_{\beta_{5}}$ and $\mathrm{Pu}-\mathrm{L}_{\beta_{1}}$ peaks is useless when the shoulder of the Compton peak is not identified $\left(C_{\mathrm{Pu}}<0.1 \mathrm{~g} . \mathrm{L}^{-1}\right)$, and the intensity of the $\mathrm{Pu}-\mathrm{L}_{\beta_{5}}$ and $\mathrm{Pu}-\mathrm{L}_{\beta_{1}}$ peaks is lower than the uncertainty of measurement of the Compton peak. 


\begin{tabular}{lccccc}
\hline Plutonium concentration (g.L & \\
\hline$I_{\text {Compton }}^{\text {MCDWIN }}$ (counts) & 0.1 & 1 & 5 & 10 & 20 \\
$I_{\text {Compted }}^{\text {corrected }}$ (counts) & 260437 & 225804 & 192619 & 155370 & 138913 \\
\hline
\end{tabular}

Table 6: Correction of the intensity for the Compton peak.

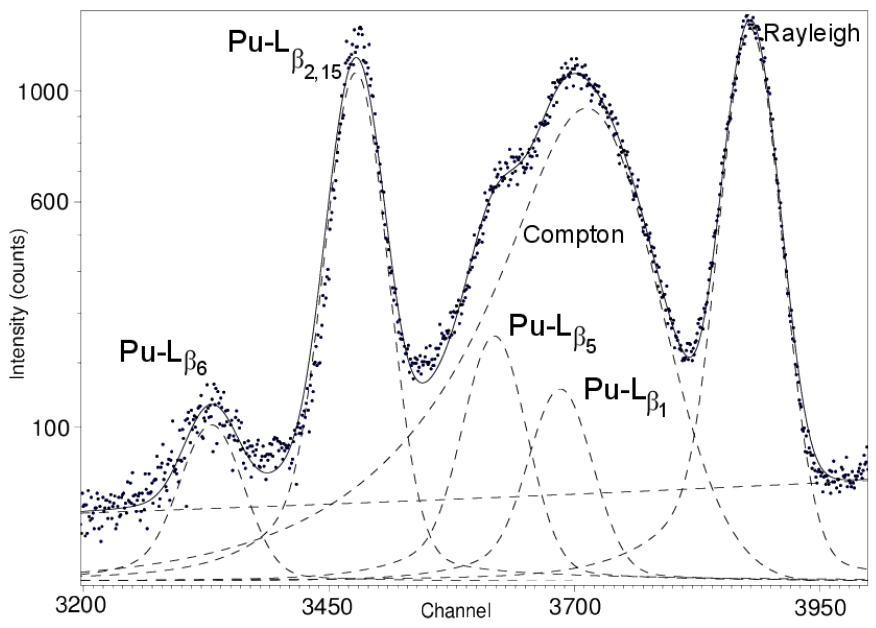

Figure 12: Fitting $\mathrm{Pu}-\mathrm{L}_{\beta_{5}}, \mathrm{Pu}-\mathrm{L}_{\beta_{1}}$ and Compton peaks for the plutonium sample at the concentration of 19.98 g. $\mathrm{L}^{-1}$.

After the subtraction of the $\mathrm{Pu}-\mathrm{L}_{\beta_{5}}$ and $\mathrm{Pu}-\mathrm{L}_{\beta_{1}}$ peaks to the Compton peak, the ratio

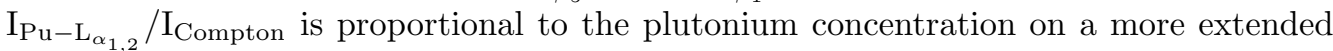
range, between 0.1 g. $\mathrm{L}^{-1}$ and 20 g. $\mathrm{L}^{-1}$ (figure 13). Thus, the sample self-absorption effects are corrected. For the plutonium, the calibration equation is in this configuration:

$$
\frac{I_{\mathrm{Pu}-\mathrm{L}_{\alpha_{1,2}}}}{I_{\text {Compton }}}=0.1108 C_{\mathrm{Pu}}
$$

where $I_{\mathrm{Pu}-\mathrm{L}_{\alpha_{1,2}}}$ is the intensity of the $\mathrm{Pu}-\mathrm{L}_{\alpha_{1,2}}$ peak, $I_{\text {Compton }}$ is the intensity of the Compton peak and $C_{\mathrm{Pu}}$ is the plutonium concentration of the sample.

\section{Conclusion}

The present study demonstrates that plutonium can be quantified in the range within 0.1 g. $\mathrm{L}^{-1}$ and 20 g. $\mathrm{L}^{-1}$ in $10 \% \mathrm{HNO}_{3}$, with an energy dispersive L X-ray fluorescence compact spectrometer. Based on the measurements of the intensity of the $\mathrm{Pu}-\mathrm{L}_{\alpha_{1,2}}$ peak, it requires to eliminate the background due to internal conversion and to take into account matrix effects. Interferences from internal conversion are minimized with a geometrical optimization of the experimental system and by subtracting the passive spectrum to the active one. The Compton correction is used in order to fix matrix effects, especially from the acid solution. This way requires an unfolding process on the Compton peak, to eliminate the overlapped peaks from $\mathrm{Pu}-\mathrm{L}_{\beta_{5}}$ and the $\mathrm{Pu}-\mathrm{L}_{\beta_{1}}$ lines. Further work 


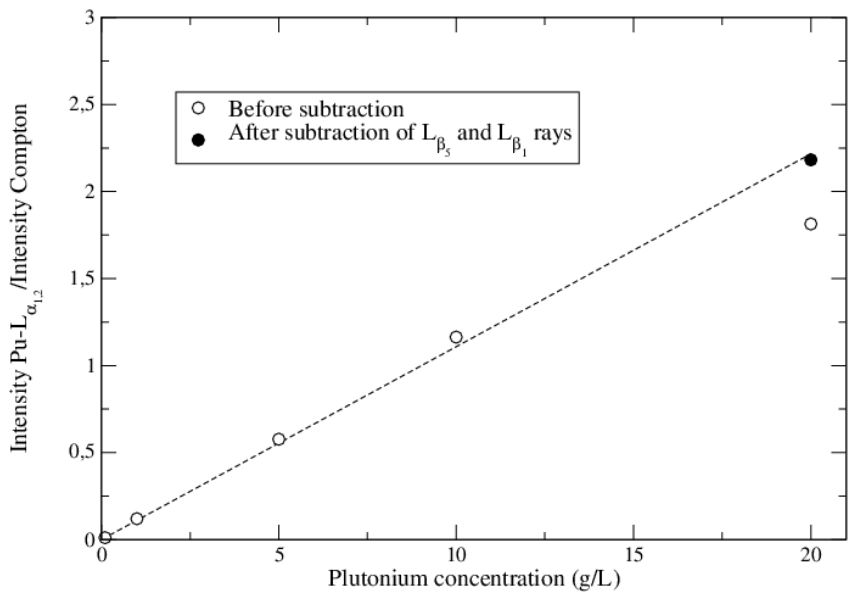

Figure 13: Ratio $\mathrm{I}_{\mathrm{Pu}-\mathrm{L}_{\alpha_{1,2}}} / \mathrm{I}_{\mathrm{Compton}}$ as a function of the plutonium concentration after the subtraction of the $\mathrm{Pu}-\mathrm{L}_{\beta_{5}}$ and the $\mathrm{Pu}-\mathrm{L}_{\beta_{1}}$ peaks.

will concern the determination of uranium and americium concentrations in these acid solutions.

\section{References}

[1] T. Hoffmann, P. Hoffmann, K.H. Lieser, Journal of Radioanalytical and Nuclear Chemistry 82 (1984) 201

[2] K.H. Lieser, P. Hoffmann, N. Pilz, Journal of Radioanalytical and Nuclear Chemistry 132 (1989) 121.

[3] T. Hoffmann, P. Hoffmann, Journal of Radioanalytical and Nuclear Chemistry 109 (1987) 419.

[4] G. Andrew, B.L. Taylor, The measurement of $\mathrm{Pu}$ and $\mathrm{U}$ in reprocessing plant solutions by tube excited K X-ray fluorescence, Journal of Radioanalytical and Nuclear Chemistry 62 (1981) 135.

[5] R.S. Day, A.R. Vigil, Journal of Radioanalytical and Nuclear Chemistry 194 (1995) 107.

[6] M.L. Collins, G.J. Havrilla, Detection Limits for Actinides in a Monochromatic, WavelengthDispersive X-Ray Fluorescence Instrument, Proceedings of the 49th Annual Meeting of the Institute of Nuclear Materials Management, Tucson, Arizona, USA (2009).

[7] G. Havrilla, M.L. Collins, V. Montoya, Z. Chen, F. Wei, Monochromatic Wavelength Dispersive XRay Fluorescence Providing Sensitive and Selective Detection of Uranium Proceedings of the 50th Annual Meeting of the Institute of Nuclear Materials Management, Baltimore, Maryland, USA (2010).

[8] G. Havrilla, M.L. Collins, V. Montoya, H. Boukhalfa, B. Cipiti, hiRX Detection of Plutonium in Surrogate Spent Fuel Matrix, Proceedings of the 53rd Annual Meeting of the Institute of Nuclear Materials Management, Orlando, Florida, USA (2012).

[9] J. Chabert, Contrôle-commande des usines de retraitement. Instrumentation, Techniques de l'ingénieur, BN3445 (1997).

[10] A. Hoover, W.S. Charlton, M.L. Fensin, A. Rajasingam, C. Rudy, S. Saavedra A. Stafford, D. Strohmeyer, S. Tobin, Measurement of Plutonium in Spent Nuclear Fuel by Self-Induced X-ray Fluorescence, Proceedings of the 49th Annual Meeting of the Institute of Nuclear Materials Management, Tucson, Arizona, (2009).

[11] H. Yoshii, K. Yanagihara, H. Imaseki, T. Hamano, H. Yamanishi, M. Inagaki, Y. Sakai, N. Sugiura, O. Kurihara, K. Sakai, PLOS one, Volume 9, Issue 7 (2014).

[12] C.G. Worley, Advances in X-ray Analysis 52 (2008) 90.

[13] ENDF/B-VII.1 2011 Nuclear Data Library, OECD Nuclear Agency, 2011. 
[14] B.L. Taylor, B. Metcalfe, Observations on the choice of the excitation source for X-ray fluorescence determination of plutonium in solution, United Kingdom Atomic Energy Authority, HARWELL Laboratory, Oxfordshire, 1986.

[15] R.A. Dewberry, Nuclear Instruments and Methods A 403 (1998) 383.

[16] Li Wenli, G.D' Ascenzo, R. Curini, G.M. Gasparini, M. Casarci, B. Mattia, D.M. Traverso, F. Bellisario, Analytica Chemica Acta 362 (1998) 253.

[17] J.-P. Eberhart, Analyse structurale et chimique des matériaux, DUNOD, Paris, 1989.

[18] B. Beckhoff et al., Handbook of Practical X-Ray Fluorescence Analysis, SPRINGER, Berlin, 2006.

[19] R. Vié le Sage, J.P. Quisefit, R. Dejean de la Bâtie, J. Faucherre, X-Ray Spectrometry 8 (1979) 121

[20] R.J.C. Brown, M.J.T. Milton, Trends in Analytical Chemistry 24 (2005) 266.

[21] R.D. Deslattes, E.G. Kessler, P. Indelicato, L. de Billy, E. Lindroth, J. Anton, Review of Modern Physics 75 (2003) 35.

[22] S.T. Perkins, D.E. Cullen et al., Tables and Graphs of Atomic Subshell and Relaxation Data Derived from the LLNL Evaluated Atomic Data Library (EADL), Z=1-100, UCRL-50400, Vol. 30, Lawrence Livermore National Laboratory (1991).

[23] M.C. Lépy, Presentation of the COLEGRAM software, Note Technique LHNB/04/26 (2004)

[24] M.C. Lépy, J. Plagnard, L. Ferreux, Applied Radiations and Isotopes 66 (2008) 715 